\title{
Hydrogen Transport through Dense and Porous Membranes for Fuel Cell Applications
}

\author{
N. C Nwogu, A. Alkali, \\ Ideas Research Instituite, Robert Gordon University, Riverside Eas, Garthdeeroad, Aberdeen, AB107GJ, UK \\ E. Gobina* \\ Centre for Process Integration and Membrane Technology, School of Engineering \\ The Robert Gordon University, Riverside East Garthdee Road, Aberdeen AB107GJ. United Kingdom \\ *Corresponding Author's
}

\begin{abstract}
In this work the design of a nano structured ceramic membrane is carried out for fuel cell applications. However the innovation is that a membrane porous network is modified through its immersion in silica based solution and in a palladium solution to form composite membrane. Subsequently, the development of hybrid ceramic gas separation membrane elaborates on the recovery of hydrogen from fuel reforming unit for use in fuel cell applications. To enhance the efficiency of the fuel cell, clean hydrogen using membranes with a high permeability and selectivity for $\mathrm{H}_{2}$ over $\mathrm{N}_{2}$ and $\mathrm{CO}_{2}$ are a necessity.
\end{abstract}

KEYWORDS: ceramic membrane; palladium membrane; energy security; carbon capture; hydrogen production; gas separation; fuel cell.

\section{INTRODUCTION}

Nanostructured hybrid materials have the promise to facilitate renewable energy to cover up for the anticipated energy gap and related ecological problems. Hydrogen utilization has therefore paved way to the fabrication of very operational energy generating devices including fuel cell. Highefficiency fuel cell operation from clean hydrogen can be utilized in all energy sectors, however its application in vehicular transportation and distributed power are more important. Accordingly fuel cell with clean hydrogen-rich fuel is top among solutions sort for the transitional process to a $\mathrm{CO}_{2^{-}}$ zero emission economy and a pathway to sustainable energy in the nearest future. Production of a cost efficient and sustainable clean hydrogen is among challenges which must be surmounted for the evolution from carbon based (fossil fuel) energy economy to hydrogen based economy[1]. Therefore an efficient and cost efficient technology for gas separation is highly required that will have the effect of reducing the overall expenditure of the entire system. Membrane technology at the moment is being highly applied widely in hydrogen separation. Membrane applications have remained a more energy efficient substitute to more conventional methods in gas separations. The outstanding difference in the flow rate and permeation features during the separation processes involving multicomponent gas mixtures makes the membrane a good candidate for gas separation[2]. Accordingly, inorganic membranes show brilliant evidence of chemical and physical properties, high temperature stability as well as unresponsiveness to sarcastic environment, homogenous pore structure and substantial tensile strength which will conquer the limitations of polymer membrane. Subsequently Electroless plating method for the deposition of palladium films over porous support is gaining increasing attention and preferred over other methods due to its ease of coating over any surface of any shape[3]. Electroless plated palladium membranes also have excellent resistance to corrosion, involve simple equipment and low cost and also avoids accumulation of the deposits around the substrate edges to ensure uniformity of coating. However, it also has its drawbacks such as its time consuming nature as a result of the several treatment steps involved and also the threat of impurities which are usually encountered during the sensitization and activation step prior to electroless plating. The sensitization and activation steps make the electroless plating process prone and susceptible to contamination from Tin, Sn[4] impurities which may lead to less active palladium layer and by implication result in low hydrogen flux. In the conventional electroless plating process, the major problem is how to achieve uniform densification of the palladium layer and also prevent mass transfer from the film into the solution. Prior to the deposition of the metal on the support, the 
sensitization and activation steps are carried out on the porous ceramic substrate so as to create catalytic sites on the non-metallic surfaces and to also stimulate the adsorption of the metal ions, enhance strong adhesion of the Pd nuclei on the substrate and eliminate induction period of the metal to ensure better uniformity of coating and improved membrane quality. In this work, we developed a new method of support modification during electroless plating which skips the sensitization step and avoided the threat of Tin impurities while drastically reducing the induction time and overall duration of the electroless plating process[5].

\section{EXPERIMENTAL}

In this work two membrane supports were designed. A conventional $15 \mathrm{~nm}$ pore size alumina ceramic membrane with an effective permeable length of $358 \mathrm{~mm}$, outer and inner diameter of $10 \mathrm{~mm}$ and $7 \mathrm{~mm}$ respectively and membrane surface area of $0.0062 \mathrm{~m}^{2}$ used for gas permeation experiment.

For the second membrane, thin Pd films were deposited on different ceramic $\alpha$-alumina supports of $30 \mathrm{~nm}$ average pore size. The porous alumina support has the specification inner diameter, $7 \mathrm{~mm}$, outer diameter $10 \mathrm{~mm}$, effective length $=0.34 \mathrm{~m}$. The support was first dried at $65^{\circ} \mathrm{C}$ in an oven for 2 hours to remove any moisture and stored for 4 hours at room temperature. The support was then calcined at $873 \mathrm{~K}$ for 24 hours and stored overnight at room temperature after which it was modified through a 2 step sensitization and activation procedure in order to seed it with Pd nuclei to create catalytic sites and ensure in a uniform deposition of the metallic layer. A second $\alpha$-alumina support was prepared based on the same procedure as the first support. A $5 \mathrm{mM} \mathrm{Sn}$ solution and $5 \mathrm{mM} \mathrm{d}[4]$ solution was used as sensitization and activation solutions respectively. Both supports were sealed at both ends to prevent internal deposition before being immersed in the sensitization solution for 5 minutes followed by rinsing in distilled water. In the conventional electroless plating, the first support was immersed in the sensitization solution for 5 minutes and rinsed with distilled water. The support was then rinsed with the activation solution for another 5 minutes and again rinsed in distilled water. This procedure is repeated 10 times to obtain a more uniformly seeded support. After the sensitization and activation procedure, the seeded support was dried overnight at room temperature. For the new method, the second support was modified with Boehmite sol through the sol gel process or dip coating method prior to the activation step after which it was inserted in the $\mathrm{Pd}$ solution for 5 minutes and rinsed with distilled water. The procedure was repeated 10 times. The sensitization step was not involved in this case. For the sol gel process, a Boehmite solution of $46.1 \mathrm{~g}$ $\mathrm{AlOOH}$ dissolved in $760 \mathrm{~mL}$ distilled water was prepared. The support was dipped into the solution for 30 minutes under continuous stirring after which it was removed and dried at $65^{\circ} \mathrm{C}$ for 2 hours. This procedure was repeated 3 times which implies that 3 sequential dips were carried out.

Figure 1 depicts a nano structured modified commercial alumina ceramic membrane

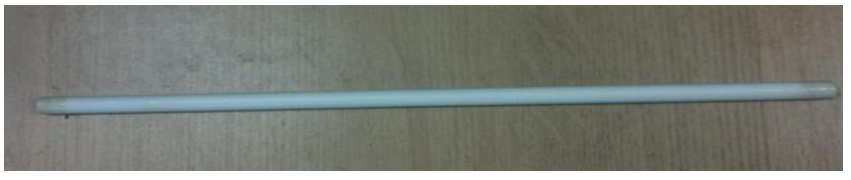

Figure 1. Nano-structured Composite

Figure 2 shows a schematic diagram of the permeation set-up used for a selective hydrogen production and recovery through a hybrid ceramic membrane.

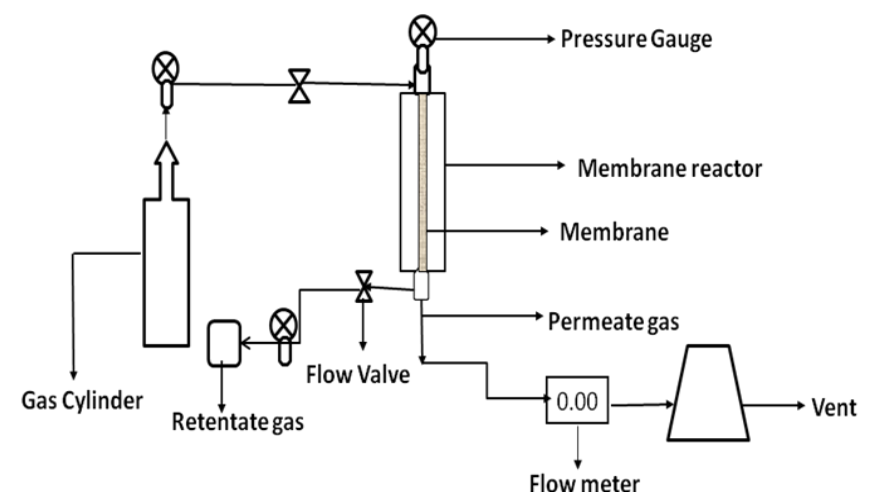

Figure 2: Experimental set up of a gas permeation cell

\section{RESULTS AND DISCUSSION}

Figure 3 depicts a plot of the flow rate of $\mathrm{H}_{2}, \mathrm{CO}_{2}$, $\mathrm{O}_{2}$ and $\mathrm{N}_{2}$ gases versus pressure drop for the commercialized $15 \mathrm{~nm}$ ceramic membrane while figure 4 is an SEM image of its inner surface. From the graph it can be observed that hydrogen gas permeated faster with increase in feed pressure through the modified ceramic inorganic membrane more than the other three single gases, $\mathrm{O}_{2}, \mathrm{~N}_{2}$ and $\mathrm{CO}_{2}$. Accordingly hydrogen gas with molecular weight of 2 had the highest flow rate of 5.0451/min above 4bars. Similarly, Figure 5 shows the morphology of the composite palladium membrane with a thickness of $2 \mu \mathrm{m}$. Figure 6 and 7 respectively show the transport of Hydrogen through the palladium composite membrane at temperature ranging from $623 k-723 k$. Sievert's law was observed to hold for these temperatures. 


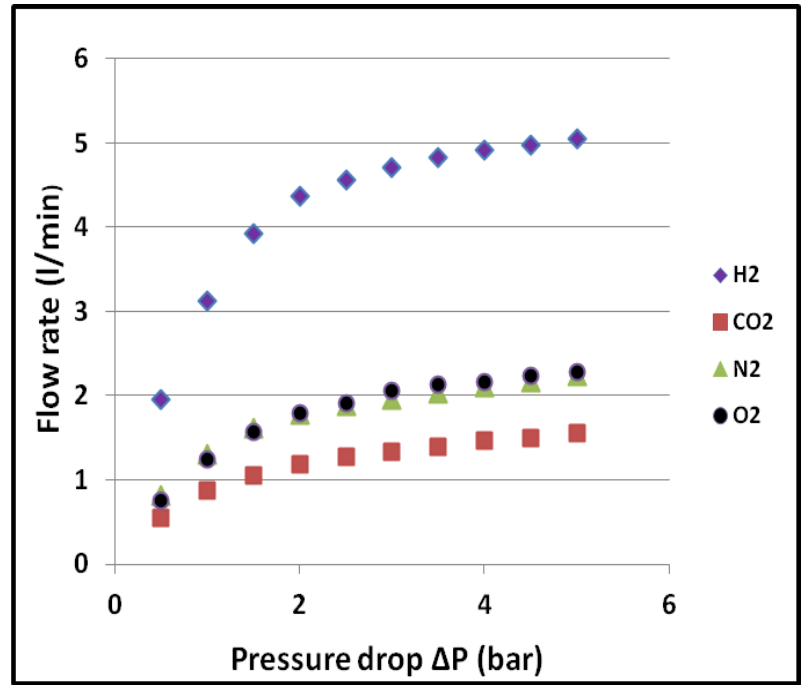

Figure 3: Effect of Pressure drop on $\mathrm{H}_{2}, \mathrm{~N}_{2}, \mathrm{CO}_{2}$ and $\mathrm{O}_{2}$ gases flow rate

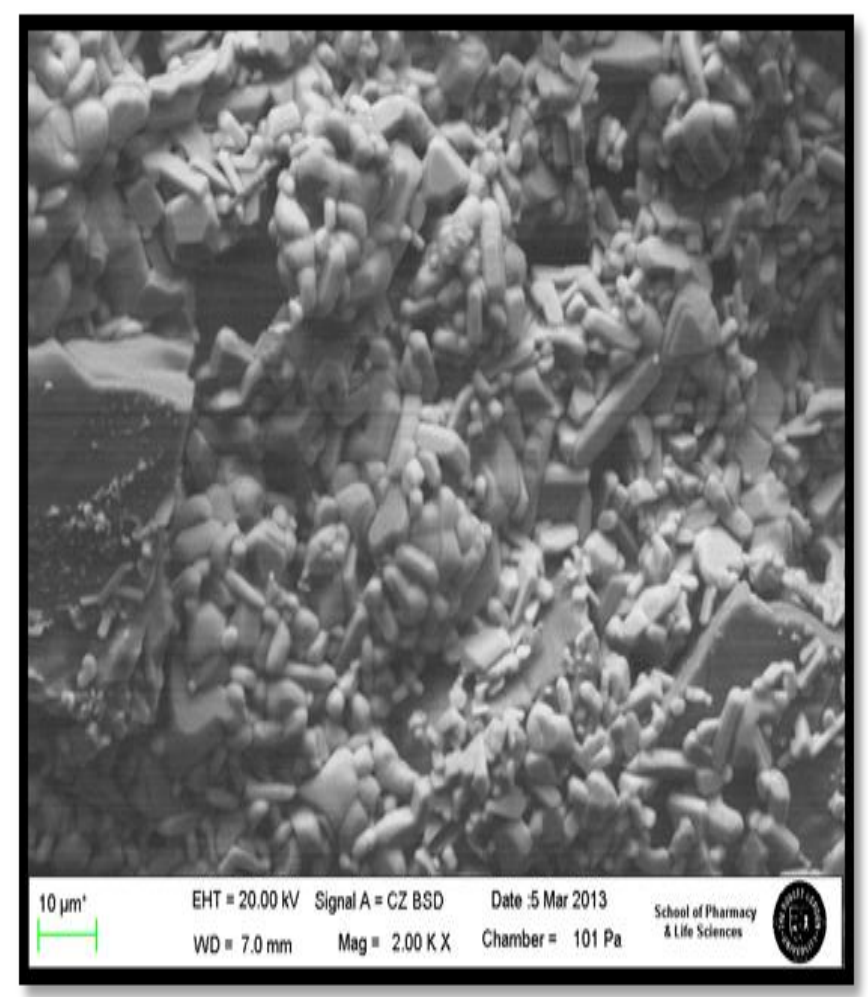

Figure 4 is the SEM image of the ceramic membrane

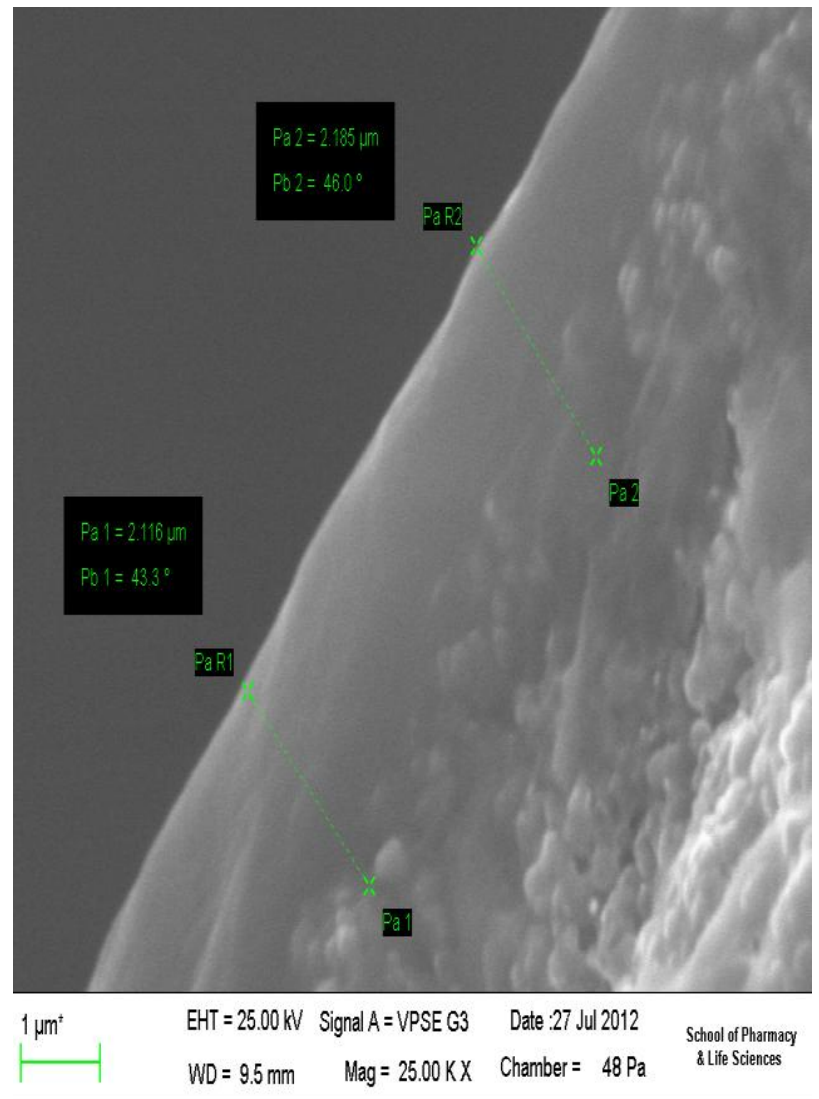

Figure 5 SEM image of the palladium membrane

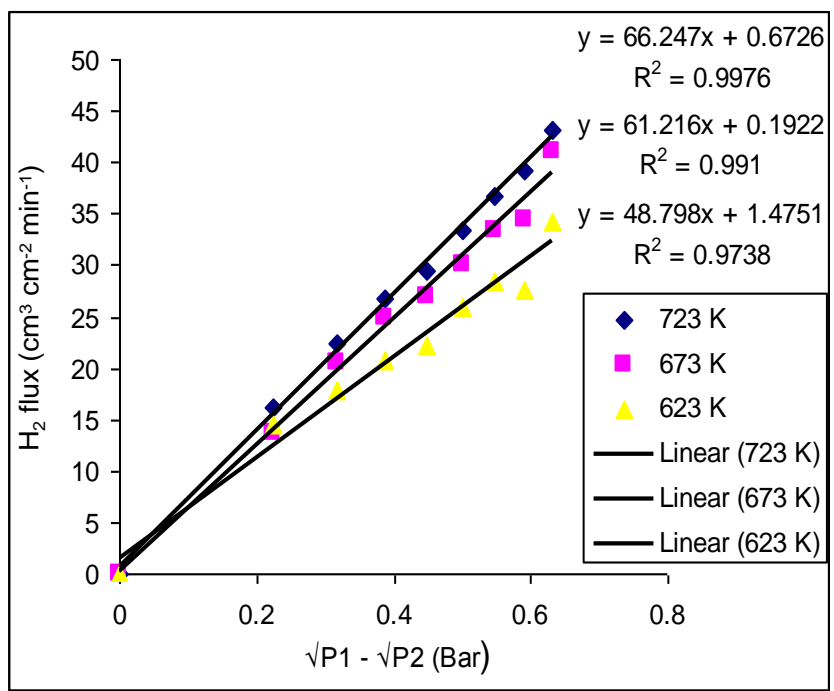

Figure 6. Effect of temperature on Hydrogen transport through the palladium composite membrane 


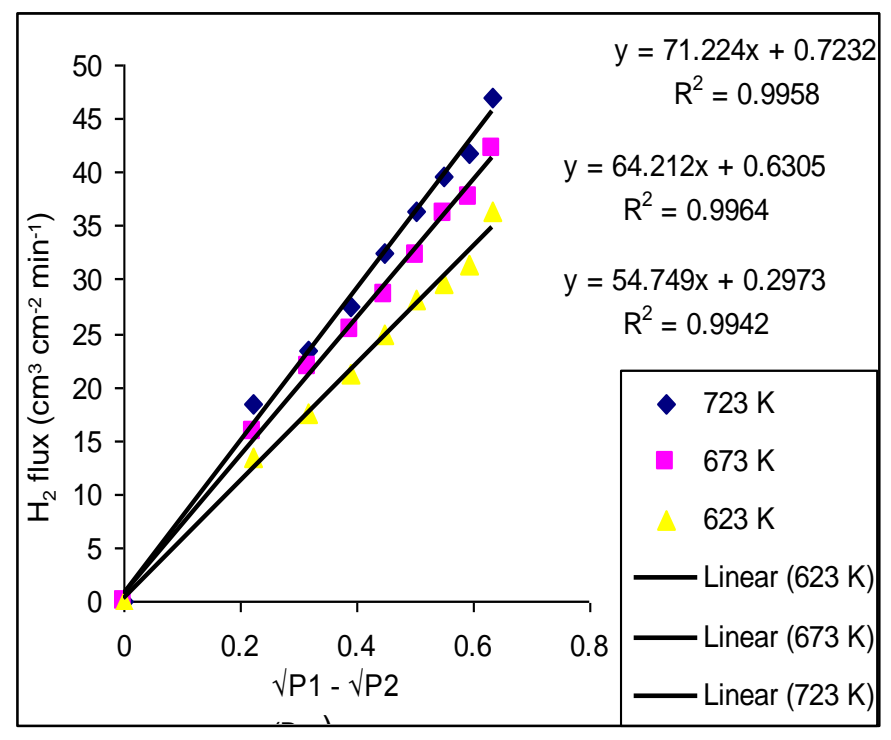

Figure 7. Effect of temperature on Hydrogen transport through the palladium composite membrane

\section{CONCLUSION}

Single gas permeation tests carried out using the ceramic and palladium composite membrane have shown that the membranes exhibits good performance and higher permeability of hydrogen gas with high flow rate. For composite palladium membrane, a thickness of about $2 \mu \mathrm{m}$ was achieved for both Palladium membranes prepared with and without sensitization. The $\mathrm{H}_{2}$ flux increased with temperature for the palladium membrane prepared with sensitization It can be observed that skipping the sensitization step increased the hydrogen flux. This indicates that there was some hindrance to hydrogen permeation during sensitization which was avoided by skipping the sensitization step during preparation of the second palladium membrane. Skipping the nsitization tep lso reduced the induction period during the plating of the second palladium embrane. Moreover, the time duration for the lectroless plating was reduced by about 1 hour which ensured a more effective plating process devoid of contamination. Overall, the results have shown that both the ceramic membrane and the palladium membrane have a high level of hydrogen gas electivity characteristics which is a good indication that they can be installed in a fuel processing unit for $\mathrm{H}_{2}$ recovery from the rich $\mathrm{CO}_{2}$ stream. Work is currently being undertaken to optimize the performance of these novel systems for various applications.

\section{REFERENCES}

[1] Edwards, P. P., Kuznetsov, V. L., David, W. I., \& Brandon, N. P. (2008). Hydrogen and fuel cells: towards a sustainable energy future. Energy Policy, 36(12), 43564362

[2] Nwogu, N. C., Gobina, E., \& Kajama, M. N. (2013). Improved Carbon Dioxide Capture Using Nanostructured Ceramic Membranes. Low Carbon Economy, 4, 125.

[3] Zhang, X., Xiong, G., \& Yang, W. (2008). A modified electroless plating technique for thin dense palladium composite membranes with enhanced stability. Journal of Membrane Science, 314(1), 226-237.

[4] Xu, L.N., Liao, J.H., Huang, L., OU, D.L., Zhou, K.C., Zhang, H.Q., Gu, N., Liu, J.Z. (2002). A new activation method for electroless metal plating: Palladium laden via bonding with self-assembly monolayers. Chinese chemical letters, vol. 13. No. 7. 687-688.

[5] Balamurali K.R.N., Choi, J., Harold, P.M. (2006). Electroless plating and permeation features of $\mathrm{Pd}$ and $\mathrm{Pd} / \mathrm{Ag}$ hollow fiber composite membranes. 